\title{
Melilla y la fiebre minera en el primer cuarto del siglo $\mathrm{xx}$ *
}

Maria Rosa de Madariaga

Desde finales del siglo XIX $y$, sobre todo, principios del $X X$, Melilla y sus alrededores viven un "sindrome" que no dudamos en calificar de "fiebre minera". Prospecciones, denuncias se suceden sin interrupción en una carrera desenfrenada por obtener concesiones de investigación o de explotación de yacimientos mineros.

Pero la situación legal de cada mina seguía estando mal definida hasta la promulgación de un reglamento minero cuya ausencia provocaba rivalidades entre grupos industriales y gobiernos.

(*) Este artículo es una refundición sintetizada (con algunos aditamentos para la ocasión) de los capítulos II y III, volúmen II, de mí tesis de doctorado de historia $L$ 'Espagne et le Rif. Pénetration coloniale et resistance locales (1909-1926), 2v.(414, 286 p.), Universidad de París I (Panthéon-Sorbonne). Tesis reproducida por el Taller Nacional de Reproducción de Tesis (Lille, Francia) 
¡Oh, hijo mio, oh, Yebel Haman!

¡Tú eres la causa de que no tengamos la paz!

¡Tus aguas son frescas, hacen crecer árboles frondosos en tus flancos!

Canción popular rifeña

\section{Las potencias occidentales y la cuestión minera en Marruecos}

Según el artículo 112 del Acta de Algeciras, un firman jerifiano fijarfa las condiciones de concesión y explotación de las minas y canteras. del Imperio de Marruecos. Aunque correspondía al Majcén elaborar el Reglamento Minero para Marruecos, éste debía, no obstante, inspirarse en las legislaciones extranjeras, lo que limitaba el poder del sultán para decidir en la materia. Cada una por su lado, dos potencias, Francia y Alemania, trataban por todos los medios de imponerse como inspiradoras de dicho Reglamento. Aunque en 1906, después de la Conferencia de Algeciras, todo hacía suponer que sería Alemania la que se impondría, fue Francia la que, gracias a un hábil y sutíl juego de influencias con el Majcén, consiguió imponerse. El 23 de junio de 1908, el Sultán Abd-el-Aziz encargaba al ingeniero francés Porché la redacción del Reglamento Minero. Más adelante, el nuevo sultán, Mulay Hafid, ratificó la decisión de su hermano de confiar a Porché la redacción de dicho Reglamento, lo que Porché haría en abril-mayo de 1909.

Francia deseaba que el examen del Reglamento por el cuerpo diplomático de Tánger no fuese más que una cuestión de pura forma, $y$, con este fin, propuso una conferencia, que se celebraría en París, limitada a los cuatro estados que estimaba más calificados para elaborar el Reglamento minero definitivo, a saber, Francia, Alemania, España y Gran Bretaña. La conferencia inició sus trabajos el 3 de noviembre de 1909 y el 19 del mismo año y més se puso de acuerdo sobre un proyecto de Reglamento en 73 artículos, que retomaba lo esencial del proyecto Porché. Los trabajos de la Comisión terminaron el 7 de junio de 1910 con la firma de un Protocolo y de un proyecto de Reglamento que los gobiernos interesados aprobaron ulteriormente.

En virtud del dahir jalifiano del 20 de enero de 1914, el 
Reglamento minero fue promulgado y, en conformidad con el artículo 3 de dicho dahir, se constituyó, para la zona española, la Comisión de Litigios Mineros de Marruecos compuesta de dos miembros permanentes: un árbitro representante del Jalifa y un superárbitro nombrado por el rey de Noruega; el tercer árbitro era designado por el gobierno del país demandante. Por otro lado, el ingeniero español de minas Gaytán de Ayala, jefe del Servicio de Minas del Protectorado, participaba asimismo en los trabajos de la Comisión como delegado del Jalifa, aunque sin derecho a voto.

La Comisión Arbitral inició sus trabajos en abril de 1914, pero a fines de julio del mismo año los suspendió a causa de la guerra, para reanudarlos en la primavera de 1919. La Comisión emitió sus primeras sentencias en noviembre de 1919. No obstante, durante el verano de 1914, el superárbitro concedió permisos provisionales de explotación a cuatro empresas: la Compañfa Española de Minas del Rif (27 de julio de 1914), la Compañía Norte Africano (27 de julio de 1914), la compañía La Alicantina (27 de julio de 1914) y, por último, la Sociedad SETOLAZAR (23 de noviembre de 1914).

De las 497 peticiones presentadas a la Comisión Arbitral en 1914, se reconoció, previo examen, que 290 correspondían a la zona francesa, 203 a la zona española y 4 a la zona de Tánger. En lo que respecta a las 203 peticiones relativas a la zona española, se concedieron, entre la primavera de 1920 y la de 1922,15 permisos de explotación (1 inglés y 14 españoles) y 27 permisos de investigación ( 2 ingleses, 18 españoles, 3 franceses y 4 neerlandeses).

Conviene señalar que el proyecto de Reglamento Minero redactado por Porché y aprobado, con ligeras enmiendas por las potencias interesadas, favorecía a los concesionarios en detrimento de los prospectores independientes, es decir de los que no trabajaban por cuenta de una gran sociedad. En efecto, desde el momento en que los concesionarios podía proceder a investigaciones en los perímetros concedidos, a los prospectores no les interesaba explorar zonas cuyos beneficiarios, en caso de descubrimiento de una mina, no serían ellos sino los concesionarios. Otras disposiciones favorecían asímismo a las grandes sociedades en detrimento de los pequeños prospectores. $\mathrm{Si}$ los gastos de prospección no eran muy elevados, si lo era, en cambio, el canon de producción, de suerte que las grandes sociedades podían pasar mucho más fácilmente que los pequeños prospectores, que no disponian de capitales, de la fase de prospección a la de explotación. 


\section{Las riquezas mineras del Rif: mitos y realidades}

"Dícese que en una montaña que en el interior se levanta existe una mina de oro de gran riqueza...": con estas palabras el africanista español Gonzalo de Reparaz, haciéndose eco de un viejo mito rifeño, evocaba en su obra Política de España en Africa, publicada en 1907, las riquezas del $\mathrm{Rif}$ en general.

En lo que respecta a las "riquezas mineras" efectivas del Rif central, cuyo territorio seguía inexplorado y era, por consiguiente, mal conocido, las únicas informaciones de que se disponía a principios del siglo XX eran las divulgadas en Melilla por los propios habitantes de la región. Existía también una vieja tradición basada en geógrafos árabes de la Edad Media como El Bekri (muerto en 1094 de la era cristiana) y de autores del siglo XVI como León el Africano.

Este último en su obra Descripción de Africa se refiere, en efecto, en varias ocasiones, en la parte consagrada a "El Rif, región del reino de Fez", a las riquezas mineras, particularmente de mineral de hierro. Así, en relación con Melilla (Melela), dice: “... Fue una ciudad muy próspera porque era la capital de la región y porque posefa un gran territorio de donde se sacaban grandes cantidades de hierro..." '. Según León el Africano, también el territorio de los Beni Saŕd encerraba riquezas mineras:

"Extraen del suelo gran cantidad de hierro... y cada maestro minero posee su propia casa cerca de la mina junto con su ganado y su talleren donde purifica el hierro. Los mercaderes transportan éste a Fez en forma de lingotes, ya que los mineros no saben transformarlo en barras. Lo que se vende sirve para

(1) León El Africano, Description de l'Afrique, París, Publication de l'Institut des Hautes Etudes Marocaines N². LXI, Librairie d'Amérique et d'Orient, Adrien Maisonneuve, 1981, Vol. I, p. 289-290. León El Africano añade que también se sacaban grandes cantidades de miel, de donde, según él, se derivaba el nombre de Melela (Melilla), que significaba "miel" en lengua africana. A. Epaulard, traductor de esta obra a partir del italiano, y autor, junto con TH. Monod, H. Lhote y R. Mauny, de la edición crítica, aclara este punto como sigue: “Miel se dice tament en berebere; en realidad, Melilla es la transposición árabe de tamelith, lugar escalonado en gradas; la ciudad estaba, en efecto, construida en una escarpadura rocosa". ibid., p. 290 , nota 625 . 
Melilla y la fiebre minera en el primer cuarto del siglo XX

fabricar herramientas tales como azadas, hachas, hoces y también armas para estos campesinos, porque de ese hierro no se puede obtener acero" 2 .

Por último, León el Africano se refiere al gran mercado que se celebraba los sábados en Uardán, al que acudía una multitud de mercaderes de hierro y en el que los intercambios comerciales consistran principalmente en el trueque de arneses de caballería y aceite por hierro 3.

Esta obra de León el Africano, escrita hacia mil quinientos veinte y tantos, atestigua pues no solo la existencia de mineral de hierro en algunos territorios del Rif, sino también su explotación, aunque fuese con métodos rudimentarios, por los propios habitantes de la región a principios del siglo XVI. Esta explotación fue sin duda cesando con el tiempo hasta interrumpirse por completo, pero puede que entre los rifeños quedase memoria de esta vieja tradición que se fue transmitiendo de generación en generación. No mentran, pues, del todo los habitantes de la región cuando afirmaban que su territorio encerraba, por lo menos partes de él, riquezas mineras.

Pero junto a esta realidad innegable, coexistía inevitablemente el mito: grutas o cavernas que encerraban tesoros escondidos, montañas de oro o de plata. Así, respecto del territorio de los ait Waryaghar (beni Uriaguel), se contaba, según una vieja leyenda, que el yebel Hamam contenía oro. A esta montaña es a la que Gonzalo de Reparaz hace alusión en las palabras que hemos citado al principio de este artículo. Según otros autores, como E. Biarnay, el yebel Hamam era para los ait Waryaghar un bloque de plata maciza, codiciado por los europeos desde hacía más de cuatro siglos. A propósito de esta montaña se cantaba en el Rif un izri (plural izran), es decir, una canción, que hemos insertado encabezando este artículo, en la que, según E. Biarnay, se podía notar cierta inquietud 0 aprensión respecto del futuro 4 .

(2) Ibid., p. 293.

(3) Ibid., p. 294-295. En relación con este mercado, los autores de la edición crítica anotada suponen que quizás se tratase del suk es-sebt actual de los Temsamán que sustituiría al de los Uardán al borde del río Amekrán, p. 295, nota 652.

(4) E. Biarnay, "Notes sur les chants populaires du Rif", Archives Berbères, 1915. vol. 1, p. 35 . 
María Rosa de Madariaga

Aún a finales del siglo XIX, viajeros como Moulièras, autor de la famosa obra Le Maroc inconnu, para quien el Rif sería una especie de nuevo Perú o un El Dorado, suplían frecuentemente la falta de información con la leyenda y el mito. Así, en relación con el territorio de los ait Waryaghar, además de la leyenda sobre el yebel Hamam, se créa, todavía en 1917, que dicho territorio era de una riqueza extraordinaria y que en Alhucemas había minas de hierro ${ }^{5}$. Fue esta leyenda sobre las riquezas mineras de los ait Waryaghar la que atrajo hacia Mohamed ben Abd-el-Krim El Jatabi a toda una serie de personas y de grupos, ávidos de obtener de él concesiones mineras, antes de 1921 y durante la guerra del Rif (1921-1926). Después de vencido el movimiento de resistencia rifeño y ocupado el Rif central, los estudios geológicos efectuados en el territorio de los ait Waryaghar, particularmente en el famoso Yebel Haman, demostraron que esas "riquezas mineras" no existran ${ }^{6}$.

En cambio, los yacimientos mineros de Beni Bu Ifrur sí eran una realidad tan indiscutible como los importantes beneficios obtenidos por la Compañfa Española de Minas del Rif (C.E.M.R.) a partir de 1915.

En los primeros años del siglo $\mathrm{XX}$, la historia del Rif, particularmente la del Rif oriental, está estrechamente asociada a la presencia de un personaje, apodado ya sea El Rogui (el Pretendiente), ya sea Bu Hamara. Haciéndose pasar por Mulay Mohamed, hijo mayor del sultán Mulay Hasán I, ejerció su poder sobre las poblaciones de esta región hasta diciembre de 1908.

Este personaje, cuyo verdadero nombre era el de Yilali ben Mohamed El Yusfi Ez-zerhuni, era, como su nombre indica, oriundo de Zerhun. Efectuó sus estudios en Fez, según algunos biógrafos en la

(5) Estudios relativos a la geología de Marruecos, Instituto Geológico de España, Madrid, 1917, p. 21.

(6) "Por lo que se refiere a las investigaciones llevadas a cabo en la kabila de Beni Urriaguel y yebel Hamman, de las que tanto se esperaba, no se ha encontrado vestigio de mineral ni de rocas hipogénicas, base para la formación del mineral, y puede decirse que todo el territorio es antiguo y pizarroso", José Guillermo Sánchez, Nuestro Protectorado-El Rify Yebala, Madrid, 1930, p. 67. 
Madrasa de El Qarawiyin, donde aprendió los principios del derecho (usul al-fiqh), la gramática, la filosoffa, etc., y adquirió asímismo conocimientos de matemáticas y geometría?

Después de terminados sus estudios, obtuvo, al parecer, un empleo oficial en el Majcén y fue secretario de Mulay Omar, gobernador de $\mathrm{Fez}^{8}$, y muhandis (topografo del ejército) ${ }^{9}$.

Por razones mal conocidas, Yilali Ez-zerhuni cayó en desgracia y hasta fue arrojado en prisión durante algún tiempo ${ }^{10}$. En cualquier caso, abandono la Corte y su país para dirigirse a Argelia en donde conoció en la zagüía de Mostaganem al xeij Sidi Abd-el-Kader ben Abba que pertenecía a la cofradía Derkaua y que lo inició en las prácticas de la magia ".

De regreso en Marruecos, viajo por varias regiones y participo en la campaña contra el tertib ${ }^{12}$. Ya durante el año de 1902, empezaron a circular en Fez noticias sobre la presencia de un hombre que, montado en una burra (de ahi el apodo de Bu Hamara, el hombre de la burra), recorría los zocos tratando de reconciliar a las tribus e invitándolas a unirse y oponerse a la reforma fiscal del tertib ${ }^{13}$. Hábil orador, sabía como seducir a su auditorio en los zocos y en las mezquitas rurales.

Durante sus peregrinaciones, fue en las regiones de los Ghiata y de los Hiaina donde sus talentos de mago tuvieron al principio mayor

(7) Eduardo Maldonado, El Rogui, Tetuán, Instituto General Francisco Franco, 1949. p. 36.

(8) Ibid., p. 37.

(9) Abdallah Laroui, Les origines sociales et culturelles du nationalisme marocain (1830-1912), París, François Maspero, 1980, p. 355.

(10) Eduardo Maldonado, op. cit., p. 38.

(11) Idem. Véase también Abdallah Laroui, op. cit., p. 355.

(12) El tertib era el impuesto que trató de introducir el sultán Mulay Abd-el Aziz, primero en 1901 y luego en 1903, conforme al cual el impuesto coránico como tal desaparecía y quedaba englobado en un impuesto único que estaban obligados a pagar por igual los súbditos extranjeros y protegidos y los marroquíes sin excepción. Esta reforma tributaria fue muy mal acogida por la población marroquí que veía con malos ojos la supresión del impuesto coránico y la equiparación fiscal de los musulmanes a los infieles. La palabra tertib significa reglamento, es decir que el impuesto tomó el nombre del texto destinado a promulgarlo. Véase a este propósito José Antonio Sangroniz, Marruecos, Madrid, 1926, 24. ed., p. 319 320, y Paul Bernard, Les anciens impots de l'Afrique du Nord, 1925, p. 20-21.

(13) Eduardo Maldonado, op. cit., p. 97. 
influjo en las poblaciones ${ }^{14}$. Su fama de hombre dotado de un poder de taumaturgo no tardó en difundirse.

Del discurso mesiánico pasó pronto al discurso político sobre el mal gobierno. Fue a partir de ese momento cuando Yilali Ezzerhuni empezó a hacerse pasar por el príncipe Moulay Mohamed que, habiendo escapado de la cárcel en donde su hermano el sultán Mulay Abd-el-Aziz lo tenía encerrado, recibió de Dios la misión de arrancar a Marruecos de la influencia de los cristianos, a quienes el sultán se habra vendido ${ }^{15}$.

En noviembre de 1902 fue proclamado sultán en Taza donde se pronunció la oración en su nombre. La mahalla compuesta de 15000 hombres, enviada por el sultán fue derrotada por los partidarios de Bu Hamara cuya victoria sobre las tropas del Majcén contribuyó a aumentar su prestigio entre las tribus de los alrededores de Taza que le prestaron juramento de fidelidad. Otra mahalla enviada por el sultán consiguió recuperar Taza el 29 de abril de 1903. Pero si Bu Hamara perdía esta ciudad, ocupaba el 14 de julio de 1903 Uxda, la cual, a su vez, recuperaron un mes más tarde las fuerzas del sultán, después de recurrir, como ya lo habían hecho en el caso de Taza, a la corrupción. Tras ocupar de nuevo Taza, Bu Hamara volvió a perderla al cabo de algunos meses y sus intentos de recuperar Uxda fallaron debido, en primer lugar, a la ayuda prestada por las autoridades francesas de Argelia a las tropas del Majcén y, luego, a la defección de algunas tribus que le retiraron su apoyo. No teniendo más remedio que levantar el sitio de Uxda, fue a instalarse en Seluán donde reinó como dueño absoluto hasta que las tribus, primero del Rif central, y luego de Guelaya, exasperadas por sus exacciones y poder tiránico, se sublevaron contra él obligándole a abandonar el Rif el 4 de diciembre de 1908.

La instalación de empresas mineras europeas en el Rif a principios del siglo XX está estrechamente relacionada con la persona de Bu Hamara quien, olvidando pronto sus exhortaciones a la lucha contra la penetración extranjera, de que se había valido para ganar a su causa a las tribus del Rif oriental, se convertía en uno de sus principales agentes.

(14) Ibid., p. 62. Véase también Abdallah Laroui, op. cit. p. 355. p. 355.

(15) Eduardo Maldonado, op. cit., p. 97-98. Véase también Abdallah Laroui, op. cit. 
Tanto los rifeños que acudran todos los años a Argelia para efectuar faenas agrícolas en las granjas y viñedos de los colonos franceses, como los que acudían a Melilla, solían aportar muestras de pedruscos que hacian suponer la existencia de ricos yacimientos mineros en la región de Guelaya. Algunos franceses de Argelia empezaron a interesarse. Por su parte, Bu Hamara, perfectamente al corriente de la posible existencia de minas en el territorio que controlaba, vio en ello una hermosa ocasion de sacar provecho. Tratando de obtener dinero de donde fuera y sabiendo que había franceses que codiciaban las minas, entabló negociaciones con los hermanos Baille a quienes cedió a fines de 1904 la explotación de las minas de Beni Bu Ifrur por un periodo de 99 años ${ }^{16}$. Cuando Bu Hamara se instalo definitivamente en Seluán en 1905, los hermanos Baille fueron a Melilla, al tiempo que pasaban largas temporadas en Seluán, pero careciendo de capitales para financiar la explotación de las minas, entablaron con Massenet, ingeniero y financiero francés protegido del duque de Wagram, negociaciones que llevaron a los primeros a retirarse en provecho de Massenet ${ }^{17}$.

A principios de mayo de 1907, después de llegar a un acuerdo con el caíd Ben Chelal y con varios jeques de Beni Bu Ifrur, Bu Hamara acogio a Massenet con quien entabló negociaciones sobre la cesión y explotación de los yacimientos de Beni Bu Ifrur ${ }^{18}$. Después de visitar algunos yacimientos, Massenet llegó el 8 de mayo de 1907 a un acuerdo con Bu Hamara, por el cual este último concedfa a Massenet, a cambio de importantes sumas de dinero y la percepción de un canon sobre la explotación, un privilegio general de explotación de todos los minerales de plomo, cobre, oro y plata en las montañas de Guelaya. En virtud de este acuerdo, Massenet entregó a Bu Hamara, entre el 3 de junio y el 27 de noviembre de 1907, una suma total de 250.000 pe-setas ${ }^{19}$.

Por su parte, un judío argelino llamado David Charbit, natural de Orán, de donde se decía que había huido tras una quiebra fraudulenta, no tard6 en entrar en relación con Bu Hamara, cuyos principales jefes como Abd-el-Krim, amín de la aduana de Melilla, y el jerife Sidi

(16) Eduardo Maldonado, op. cil., p. 295 y 346.

(17) Ibid., p. 347.

(18) lbid., p. 348. p. 906.

(19) Boletin oficial de la zona de Protectorado español en Marruecos, año VIII, 1920. 
El Hach Fadel En-nasiri, frecuentaban la tienda de Charbit en El Polígono. Informado de las riquezas mineras de Beni Bu Ifrur, este último consiguió interesar en los negocios mineros a un grupo financiero español y se propuso para servir de intermediario entre éste y Bu Hamara. Este grupo estaba constituido por el hombre de negocios Enrique McPherson, socio del ingeniero de minas Alfonso del Valle quien habfa efectuado ya entre 1905 y 1907 estudios geológicos de los yacimientos de Uixán ${ }^{20}$. A pesar de la concesión que había hecho a Massenet, Bu Hamara, con el pretexto de que este último no había entregado la totalidad de la suma convenida en el plazo de tres meses que se le había fijado, entabló negociaciones con McPherson y del Valle con el fin de hacer con ellos un nuevo trato. Tras llegar a un acuerdo, Bu Hamara cedió las minas de hierro de Beni Bu Ifrur a los dos españoles quienes habían constituido en mayo de 1907 el Sindicato Español de Minas del Rif.

Entretanto, McPherson había entablado negociaciones con Clemente Fernández, un comerciante de carne al por mayor, quien, por intermedio del Ministerio español de Estado (Ministerio de Asuntos Exteriores), había dirigido el 25 de mayo de 1907 al sultán de Marruecos una petición con el fin de obtener la autorización de explotar dos minas situadas en el territorio de la cabila de Beni Bu Ifrur, de una superficie de 3.000 hectáreas de plomo argentífero y de 5.400 hectáreas de hierro magnético, respectivamente, la última situada en el centro del Monte Uixán ${ }^{21}$. Hay que señalar que las dos minas mencionadas por Fernández en su petición al Majcén eran las mismas que Bu Hamara había cedido a Massenet y que la segunda era la misma que había cedido a McPherson y del Valle.

Fernández, cuyo nombre está asociado a otras peticiones de con-cesiones mineras por cuenta de la Sociedad Madrileña Hispano-Marroquí ${ }^{22}$, habŕa tomado la precaución de dirigirse al Sultán, única auto-

(20) Las Minas del Rify de Setolazar, fascículo multicopiado de la Sociedad Española de Minas del Rif, Uixán, marzo, 1964, p. 1 . p. 245.

(21) Boletín oficial de la zona de Protectorado español en Marruecos, año VIII, 1920.

(22) Denuncia presentada el 4 de julio de 1907 por Clemente Fernández, en nombre de la Sociedad Hispano-Marroquí, de unas minas llamadas La Puntilla, situadas en la cabila de Beni Sicar, en la Península de Tres Forcas. Basándose en esta denuncia, la Compañía Española de Minas del Rif presentó más tarde a la Comisión Arbitral de Litigios Mineros en Marruecos una petición de concesión de un permiso de explotación de dichas minas, permiso 
ridad legftima reconocida por las potencias signatarias del Acta de Algeciras. De ahi la importancia para McPherson de llegar a un acuerdo con él, dado que la concesión hecha por Bu Hamara dimanaba de un poder considerado ilegítimo. Pero por ilegítimo que fuera, ese poder era el único existente, sin cuyo acuerdo no era posible emprender nada en el Rif oriental. Por eso, paralelamente a su gestión con el Majcén, Fernández se dirigía asimismo a Bu Hamara quien el 9 de junio de 1907 concedía "al comerciante Clemente Fernández, representante de la compañía española (la autorización) con fines de explotación de las minas próximas a Melilla, tribu de Guelaya, en conformidad con el trato convenido" ${ }^{23}$. No se especificaba el nombre de la compañía española, pero cabe pensar que quizá se tratase de la Sociedad Madrileña Hispano-Marroquí, en provecho de la cual Fernández habia hecho otras denuncias cuyos derechos cederfa más tarde al Sindicato Español de Minas del Rif tras llegar a un acuerdo con McPherson y del Valle.

Pero otros grupos españoles se interesaban asimismo por los yacimientos del Rif. La Razón Minera G. y A. Figueroa, de la familia del conde de Romanones ${ }^{24}$, envió a Melilla a dos ingenieros de la firma, los cuales redactaron un informe en el que hacian constar la riqueza de los yacimientos de Uixán y la buena calidad del mineral. Según dicho informe, el mineral se encontraba en enormes canteras, que eran minas a cielo

que obtuvo por sentencia de dicha Comisión de fecha 6 de junio de 1921. La Sociedad Wm. H. Muller \& Co., de nacionalidad neerlandesa, interpuso recurso contra dicha sentencia alegando, por una parte, que la prioridad del descubrimiento de las minas de la Península de Tres Forcas correspondía a Suárez Lorenzana, representante de la mencionada Sociedad, y, por otra parte, que la denuncia de Clemente Fernández habia sido hecha en nombre de la Sociedad Hispano-Marroquí y no de la Compañía Española de Minas del Rif. Para todo lo relacionado con este litigio, véase Archivos del Ministerio español de Asuntos Exteriores (citados de ahora en adelante M.E.E., Ministerio de Estado de España), Marruecos, Sección política, H., vol. 2543) y Boletín oficial de la zona de Protectorado Español en Marruecos, año IX, 1921, p. 486-488 y 548-556, y año X, 1922, p. 303-311 y 346-348.

(23) Boletín oficial de la zona de Protectorado español en Marruecos, año VIII. 1920. p. 245.

(24) Las letras G. y A. corresponden respectivamente a las iniciales de Gonzalo y Alvaro de Figueroa y Torres, hijos de Ignacio de Figueroa y de Ana de Torres. G. y A. Figueroa, importante empresa financiera creada por Ignacio de Figueroa en 1889, pasó a ser sociedad anónima en 1900. Por otro lado, Alvaro de Figueroa y Torres, conde de Romanones, era una importante personalidad política como jefe del partido liberal. Después del asesinato de José Canalejas en 1912, fue presidente del Consejo de Ministros. 
abierto, cerca de la costa, cuyo transporte y explotación eran fáciles ${ }^{25}$. La Sociedad G. y A. Figueroa trató entonces de convencer a Bu Hamara de que rompiese sus compromisos con Massenet y con el grupo representado por McPherson, del Valle y Fernández, para lo cual ofreció a $\mathrm{Bu}$ Hamara entregarle inmediatamente la cantidad de 250.000 pesetas que éste exigía. David Charbit, socio de McPherson, del Valle y Fernández, inició nuevas gestiones con Bu Hamara para impedir ese trato, mientras que el representante del nuevo grupo español interesado, es decir, la Sociedad G. y A. Figueroa, prometía a Bu Hamara cantidades de dinero que iban hasta un millón de pesetas ${ }^{26}$.

Tras una competencia encarnizada para obtener la concesión de las minas de Uixán, los dos grupos rivales llegaron a un acuerdo y se asociaron para fundar, en junio de 1908, la Compañfa Española de Minas del Rif, -que sucedía al Sindicato Español de Minas del Rif y que se constituyó como sociedad anónima con un capital inicial de cinco millones de pesetas en acciones liberadas ${ }^{27}$. La nueva compañía, producto de la fusión de los dos grupos capitalistas rivales, estaba formada por Enrique McPherson y Clemente Fernández, la Sociedad G. y A. Figueroa y la Casa Güell de Barcelona.

En cuanto al grupo francés representado por Massenet, aunque la concesión de Bu Hamara a este último comprendía todos los yacimientos de Beni Bu Ifrur, tuvo que contentarse con las minas de plomo de Afra. El 21 de agosto de 1907 Massenet constituyó la Compañía Norte Africano con capitales franceses, pero de nacionalidad española, cuyo primer presidente fue García Alix, antiguo ministro conservador y gobernador del Banco de España.

\section{Prospectores y denuncias mineras}

Si en la memoria de los españoles la expresión "minas del Rif" es sinónima de la empresa más importante que explotó los yacimientos mineros de Beni Bu Ifrur, es decir, la Compañía Española de Minas del Rif, hay que precisar que otras empresas menos importantes explotaron asímismo minas, particularmente en la región de Guelaya. Por su-

(25) Víctor Ruiz Albéniz, El Riff, 1912, p. 18.

(26) Eduardo Maldonado, op. cit. p. 349.

(27) Ibid., p. 406. 
puesto, su número fue limitado o hasta insignificante en relación con las numerosas denuncias y peticiones de concesiones registradas desde el principio de nuestro siglo, que testimonian una verdadera fiebre minera, una especie de fascinación alimentada por los relatos tanto antiguos como recientes sobre las riquezas que el Rif encerraba.

Desde fines del siglo XIX, individuos más o menos aventureros recorrían la región en busca de pedruscos milagrosos, anunciadores de ricos yacimientos mineros.

Uno de los más representativos de esos individuos quizá fuese un ingeniero español llamado Alberto Suárez Lorenzana, a quien un autor describe como "algo fantástico y trapacero en su conducta" ${ }^{28}$, el cual declaraba haber descubierto en 1880 y, luego, en febrero de 1908, diversos minerales, particularmente de hierro, en el territorio de la cabila de Beni Sicar, en la Península de Tres Forcas ${ }^{29}$. Declaraba asímismo haber visitado en 1887 y 1888 las cabilas de Bocoya, Beni Bu Frah, Berni Iteft, Beni Uriaguel y Beni Mezdui, en el Rif central, y haber comprado terrenos en las tribus de Beni Sicar, Beni Uriaguel y Beni Tuzin, compras que el sultán Mulay Abd-el-Aziz habra aprobado en una carta del 3 de julio de 1908 dirigida a los jefes de las cabilas mencionadas, y que otros documentos habían sancionado, particularmente una carta del ministro marroquí de Asuntos Exteriores del 11 de julio de 1908, así como una carta del propio Lorenzana al delegado del Majcén en Tánger, de fecha 31 de octubre de 1908, con respuesta de dicho delegado ${ }^{30}$. Estos descubrimientos se tradujeron en una lluvia de denuncias mineras, junto con compras de terrenos a los habitantes de los territorios en cuestión en los años de 1908, 1909 y 1910. Se atribuían a Lorenzana unas treinta denuncias mineras de sitios donde, pese a sus afirmaciones, "no había puesto el pie" ${ }^{31}$.

En los archivos del Ministerio español de Asuntos Exteriores, sección Marruecos, hay decenas de documentos relativos a peticiones de concesiones mineras.

Los documentos más antiguos corresponden a 1908 y se refieren, entre otras, a las peticiones efectuadas por Clemente Fernández,

(28) Ibid.. p. 191.

(29) M.E.E., Marruecos, Sección política, H., vol. 2543.

(30) Ibid.

(31) Eduardo Maldonado, op. cil., p. 191. 
cuyo nombre está estrechamente relacionado con las minas de Beni $\mathrm{Bu}$ Ifrur, y por el financiero vasco Horacio Echevarrieta que desempeñarfa más tarde un importante papel durante la guerra del Rif, particularmente en relación con la liberación en enero de 1923 de los prisioneros españoles retenidos por Mohamed ben Abd-el-Krim El Jatabi en Axdir, y, luego, como intermediario en las negociaciones de paz entre este último y el gobierno español en 1923 y 1925.

Para el año de 1909, no hemos encontrado más que tres peticiones de concesiones, ya que los sucesos de Melilla, cuya causa principal habían sido las obras de las compañías mineras, habían paralizado toda actividad en este sentido. Pero a partir de 1910 se reanudan, aunque sigan siendo poco numerosas. En 1911, el número aumenta ligeramente, y en 1912 y 1913, se registra un fuerte aumento. El establecimiento del Protectorado en 1912 no era sin duda ajeno a ello. Para el año de 1914, en la petición de concesión presentada por Francisco Fernández Sabasa relativa a las minas Atlaten y Gurugú, se especifica que dichas minas están situadas en los territorios de las cabilas de Beni Bu Ifrur, Beni Sicar y Mazuza, Para 1914, a pesar de que la Comisión Arbitral de Litigios Mineros en Marruecos se habŕa establecido ese mismo año, hemos encontrado tres peticiones de concesiones presentadas al Ministerio español de Asuntos Exteriores por Carlos García Alonso. Por último, para 1919, año en que la Comisión Arbitral de Litigios Mineros en Marruecos reanudó sus trabajos interrumpidos durante la Primera Guerra Mundial, hemos encontrado una petición, dirigida de nuevo al Ministerio español de Asuntos Exteriores y presentada por Camila Hasán, viuda de Salama (Samuel), de Melilla, en representación de Pablo Vallesca, Isaac Benarroch y David Charbit ${ }^{32}$. Esta petición es interesante por referirse a concesiones mineras en el yebel Hamam, en el territorio de los beni Uriaguel, el famoso yebel Hamam que según la leyenda encerraba oro o plata y para el que otras personas, particularmente Suárez Lorenzana, H. Letellier y Víctor Kiefe, éste último en representación de Camila Hasán y de los arriba mencionados, habían presentado asímismo peticiones de concesiones mineras a la Comisión Arbitral en $1914^{33}$.

Todas estas peticiones exigen algunos comentarios por nuestra

(32) M.E.E., Marruecos, Sección política, H., vol. 2542.

(33) Boletín oficial de la zona de influencia española en Marruecos, año II, 1914. 
Melilla y la fiebre minera en el primer cuarto del siglo $\mathrm{XX}$

parte. En primer lugar, entre las personas que presentaron peticiones vemos aparecer nombres que encontramos en otros lugares. Además de Clemente Fernández, al que ya hemos tenido ocasión de referimos repetidas veces, la lista es larga y reveladora: Rodrigo de Figueroa y Torres, duque de Tovar, hermano del conde de Romanones; Juan Antonio Güell, sobrino del marqués de Comillas y uno de los principales accionistas de la Compañía Española de Colonización; Carlos Levinson, consejero de la Compañfa Española de Minas del Rif y uno de los fundadores de la Compañ́a Española de Colonización; Camila Hasán, viuda de Salama, de la familia de José y Jacobo Salama, banqueros de Melilla y fundadores de la Compañ́a Española de Colonización; Pablo Vallescá, presidente de la Cámara de Comercio de Melilla y vicepresidente de la Compañía Española de Colonización; Isaac Benarroch, propietario y comerciante en Melilla y miembro del Comité de dirección de la Compañía Española de Colonización; David Charbit, cointeresado de Clemente Fernández y una de las personas que desempeñaron un papel capital en la concesión por Bu Hamara de las minas de Uixán al Sindicato Español de Minas del Rif; Francisco Setuaín y San Emeterio, Juan Olavarriaga y Félix Ortiz de Zárate, que constituirían más adelante la Compañía SETOLAZAR, anagrama de los tres nombres Setuaín, Olavarriaga y Zárate; y, por último, Kenneth Middleton, ingeniero del Morocco Minerals Syndicate Ltd., que habla hecho peticiones de concesiones mineras y comprado terrenos en nombre de esta compañía de nacionalidad británica. Se puede comprobar que, con excepción de este último, y de David Charbit que tenía la nacionalidad francesa, todos los demás corresponden a personas de nacionalidad espaffola, muchas de ellas estrechamente vinculadas a grandes intereses financieros.

Por otra parte, el número importante de peticiones para el año de 1908 prueba que las concesiones hechas por Bu Hamara a grupos capitalistas españoles y franceses alentaron a otros muchos a tratar de obtener concesiones mineras por los mismos medios. Es verdad que tanto los que esperaban obtener concesiones de Bu Hamara como los que ya los habían obtenido tomaban en general la precaución de dirigir una petición al Majcén por intermedio del Ministerio español de Asuntos Exteriores. Un ejemplo, el de Clemente Fernández, aunque éste, sin esperar la decisión del único poder habilitado para hacer ese tipo de concesiones, no tuviera entretanto el menor reparo en conseguir de Bu Hamara la misma concesión. Todos los que habian tratado de obtener concesiones 
de Bu Hamara, una vez que éste perdió todo poder en el Rif, se apresuraron a producir documentos justificativos de sus peticiones al Majcén por intermedio del Ministerio español de Asuntos Exteriores, mientras que los que hicieron sus peticiones en los años siguientes siguieron el procedimiento normal, es decir, dirigirse al Ministerio español de Asuntos Exteriores para que éste transmitiese sus peticiones al Majcén.

Suárez Lorenzana, a quien ya nos hemos referido quizá por ser uno de los más pintorescos entre sus congéneres, nos da una imagen bastante viva de esos prospectores de minas que pululaban en Melilla a principios de nuestro siglo.

Melilla, que no contaba en 1900 más que con unos 4.000 habitantes, prácticamente parapetados tras las murallas de la vieja ciudadela, en la Alcazaba y en dos barrios exteriores que empezaban a desarrollarse con una población mixta compuesta de españoles, de israelitas y de marroquíes, habŕa pasado a más de 21.000 habitantes en 1910 y los barrios exteriores alcanzaban los límites del territorio bajo soberanía española.

El crecimiento que la ciudad había experimentado después de la guerra de 1909 era el resultado de un aumento de los contingentes militares que se trasladaban acompañados generalmente de sus familias, contribuyendo así a un aumento de la población civil. Con las obras del puerto y las minas, otros elementos civiles empezaron asímismo a instalarse allí. El número de médicos, de abogados, de ingenieros no tardó en aumentar, así como el de comerciantes, obreros y artesanos. En 1920 la población ascendía a 40.564 habitantes; en 1925, a 52.488 .

La ciudad que, por sus edificios, sus avenidas bordeadas de palmeras y sus jardines, se asemejaba a cualquier otra ciudad del Levante español o de Andalucía, era, sin embargo, muy diferente por su población. Junto a los numerosos elementos militares y la población civil llegada de la Península, que se desarrollaba cada vez más, Melilla contaba asimismo con una numerosa comunidad israelita establecida desde larga fecha y que poseía en general la nacionalidad espanola. Muy activos, los judíos detentaban, en general, en sus manos una gran parte del comercio, la industria y la banca. Familias como los Benaroch, los Benchimol, los Hasán, los Salama, desempeñaron un importante papel en la vida económica de Melilla. A estas dos comunidades se sumaba la comunidad musulmana, compuesta principalmente de comerciantes instalados en El Mantelete, además de una población flotante de centenares de marroquíes 
que acudían todos los días a Melilla para vender sus mercancías y, a su vez, abastecerse. Eran precisamente muchos de estos marroquies, procedentes a veces de las cabilas del interior, los que propalaban en Melilla las noticias más extraordinarias sobre las riquezas mineras de su territorio.

Después del descubrimiento de los yacimientos mineros de Beni Bu Ifrur, aumentó la prisa en exhibir pedruscos, así como el número de los que trataban de descubrir otros yacimientos que harian su fortuna.

Fue una época desenfrenada de "descubrimientos", de denuncias, de peticiones de concesiones mineras. A menudo domiciliados en Melilla, algunos de los peticionarios de concesiones habitaban la Península, después de haber residido del otro lado del Estrecho en donde conservaban vínculos con personas que se habían establecido allí. En lo que respecta a sus profesiones, había un poco de todo: comerciantes o industriales como Arqueros Jerez, Teulón Bisso, Ferrer Gómez o Fernández Sabasa; industriales propietarios como Navarrete Díaz, o sencillamente propietarios como Ramos González; agentes de negocios como Ruiz Mira; ingenieros como Alzugaray Goicoechea y Sierra Bustamante; abogados como Tari Sánchez. Entre los peticionarios que se dirigieron a la Comisión Arbitral en 1914, habra aún mecánicos como Perea Castro, obreros mineros como Fernández y Fernández e incluso capitanes de caballería como Hernández Regalado.

Muchos de los peticionarios no eran ellos mismos los inventores de la mina, sino sencillamente los beneficiarios de los derechos concedidos por los que la habían descubierto, es decir, los prospectores. Entre estos últimos, cabe mencionar a Ruiz Pastor, Llovio Gómez y Císcar Roselló, cuyos nombres figuraban ya en los documentos mineros relativos a Marruecos del Ministerio español de Asuntos Exteriores ${ }^{34}$.

En lo que respecta al primero, su hijo Ruiz Mira presentaba en 1914 a la Comisión Arbitral una petición destinada a obtener un permiso de investigación para un perímetro de 45.000 hectáreas, sobre la base de las prospecciones efectuadas por su padre durante un viaje que decia haber efectuado al territorio de Beni Bu Yahi, en donde habla recogido muestras de mineral de hierro y de plomo ${ }^{35}$. La actividad de Ruiz Pastor como explorador de riquezas mineras en Marruecos había llevado, según

(34) M.E.E., Marruecos, sección política, H., vol. 2542.

(35) Boletín oficial de la zona de Protectorado español en Marruecos, año IX, 1921. p. 843 . 
su hijo, a varios descubrimientos de yacimientos en la zona española ${ }^{36}$. En todo caso, Ruiz Pastor había presentado en 1908 peticiones de concesiones en representación de terceros, entre otros Horacio Echevarrieta ${ }^{37}$.

En cuanto a Llovio Gómez, de quien se declaraba que habia descubierto en 1910 yacimientos de hierro y de plomo en los territorios de las cabilas de Beni Sidel y Beni Bu Ifrur, cedió en diciembre de 1912 sus derechos a José Maŕa Hernández y Hernández ${ }^{38}$.

Por último, Císcar Roselló había descubierto, entre otros, yacimientos de hierro en Bugarara (cabila de Beni Bu Ifrur) a fines de 1909 y fundado, con otros, en 1911 la sociedad civil La Valenciana, a la que sucedería en 1912 La Alicantina ${ }^{39}$, una de las cuatro empresas que explotarian y exportarían más tarde minerales en la región del Rif oriental.

Cuando no actuaban por cuenta de otros, muchos de estos prospectores, al no disponer personalmente de capitales, buscaban socios para la futura explotación del yacimiento que habían descubierto. Se fueron constituyendo asi empresas, algunas eff́meras; otras, duraderas. Hemos mencionado el caso de Císcar Roselló que fundo, junto con otros, la sociedad La Alicantina; pero muy a menudo el inventor de la mina 0 la sociedad constituida por él y sus socios cedían sus derechos a otras empresas más poderosas. Este fue el caso de un prospector, Cintas Grimas, inventor de la mina Santa Beatriz (situada en la cabila de Beni Bu Ifrur), quien, después de haber formado con otros socios una compañía designada asimismo Santa Beatriz, terminó por ceder sus derechos sobre el perímetro en cuestión a la sociedad La Andaluza constituida el 16 de marzo de $1912^{40}$.

A veces vemos cesiones de derechos en cadena. Este fue el caso del yacimiento llamado Gurugú y Atlaten, descubierto en 1910 por Ruiz Conesa, quien cedió más tarde los derechos que pudieran dimanar de este descubrimiento a Tebar Pujalte, el cual, a su vez, los cedió al conde de Peñaflorida. Este último, por su parte, cedió en 1914 sus derechos

(36) Ibid., p. 844.

(37) Petición presentada por Ruiz Pastor, en representación de Horacio Echevarrieta, para las minas Cosme y Horacito. M.E.E., Marruecos, sección política, H., vol. 2542. p. 86.

(38) Boletín oficial de la zona de Protectorado español en Marruecos, año VIII, 1920 ,

(39) Bbid., p. 903.

(40) lbid., p. 909. 
a Fernández Sabasa, quien más tarde los cedería a la Compañía Española de Minas del Rif, sociedad que se presentó como demandante para el perfmetro en cuestión en $1920^{4 !}$.

Entre otros ejemplos de cesiones de derechos en cadena, cuyo último beneficiario fue asímismo una compañía que explotaría más adelante yacimientos en el Rif Oriental, cabe mencionar las cesiones de que fue objeto la mina Navarrete, situada en el territorio de la tribu de Beni Bu Ifrur. Cándido Lobera y Girela, director del diario El Telegrama del Rif, había dirigido el 12 de febrero de 1912 al gobernador militar de Melilla una petición de concesión para esta mina, y constituido el 15 de febrero de 1910, junto con tres compatriotas. La sociedad Sindicato Minero de Melilla, la cual cedió más tarde 84 centésimas de sus derechos a Babin y Pignault, quien, a su vez, los cedió a Arthur Netter. Este último, que presentó en 1914, en nombre del Sindicato Minero de Melilla, una petición de concesión rèlativa a esta mina, cedió más tarde sus derechos a la Sociedad SETOLAZAR que se presentó como demandante para el perimetro en cuestión en $1920^{42}$.

Por último, mencionemos aún la cesión de derechos relativas 201 a la mina Marfa de la Asunción, situada en el territorio de la cabila de Beni Ulichek, para la que Rodríguez Jiménez había presentado en 1914 una petición de concesión en su nombre y como representante de Ecija y Morales y Palomares Maeso. Los dos primeros habran adquirido la parte perteneciente al último, fallecido, y más tarde, por acta de asociación notarial, de fecha de 11 de mayo de 1914, cedieron sus derechos a una sociedad civil Erby, domiciliada en Melilla, la cual los cedió, a su vez, por acta del 13 de mayo de 1920, a la Compañáa Minera Hispano Africana ${ }^{43}$. Esta sociedad, que se presentó más adelante como demandante ante la Comisión Arbitral, había sido fundada con capitales del Banco Hispano-Africano (Madrid), la sociedad anónima Arnús-Garf (Barcelona), el Crédito de la Unión Minera (Bilbao) y la Compañía Española de Colonización.

(41) Ibid., p. 898-899.

(42) Ibid., p. 913-914.

(43) Boletín oficial de la zona de Protectorado español en Marruecos, año IX, 1921, 343. 
María Rosa de Madariaga

\section{Conclusión}

Todos estos ejemplos de descubrimientos de yacimientos, denuncias mineras, peticiones de concesiones, constituciónes de empresas, ilustran bien la intensa actividad minera que se desarrollo en la zona septentrional de Marruecos en el primer cuarto del siglo XX. Aunque no alcanzara las dimensiones de la "fiebre del oro" que vivió la California del siglo XIX, no es menos reveladora de toda una época de búsqueda desenfrenada, por parte de los países más desarrollados, de materias primas para su industria en regiones del mundo aún inexploradas, que se caracteriza por la transición del capitalismo a la etapa del imperialismo, con la consiguiente expansión colonial y reparto del mundo entre las potencias occidentales. A España, cuyo desarrollo capitalista no había alcanzado en esa etapa el nivel de otras potencias europeas como Inglaterra o Francia, sólo le tocaron en ese reparto - por obra y gracia de Inglaterra, para que Francia, su rival en la carrera colonial, no se instalara frente al Estrecho de Gibraltar - las migajas: una zona montañosa y pobre en el Norte de Africa, aunque, por ser aún mal conocida y permanecer inexplorada, de ella se contasen maravillas sobre las riquezas minerales que su subsuelo encerraba. Cuando la realidad se impuso al mito, se vio que de esas riquezas fabulosas sólo existía una mínima parte. Con todo, de la explotación de esa parte, por pequeña que fuese en relación con lo que la imaginación habra forjado, algunos grupos capitalistas, sobre todo la Compañ́a Española de Minas del Rif, y en menor grado la Norte Africano, la SETOLAZAR y, por último, la Alicantina, sacaron beneficios considerables. Pero frente a estos grupos, decenas de prospectores, incansables buscadores de pedruscos por montes y valles del Rif, cuyos nombres permanecen hoy más o menos ignorados, no verían jamás realizados sus sueños de hacer fortuna. 